Volume 1 Number 2, December 2013

ISSN 2345-9387

\title{
EDITORIAL
}

\section{Climate Smart Agriculture: A Solution to adverse effects of climate change}

It is well recognized that worldwide understanding pertaining to climatic change and variations has alarmed all the nations to evolve and implement relevant strategies to resilient vulnerable environments. Mitigation and adaptation are the two major scenarios proposed to minimize the effects of climatic change. The Intergovernmental Panel on Climate Change IPCC (2007) defines climate change as any change in climate over time whether due to variability of natural processes, external force or continuous anthropogenic activities in the components of the atmosphere or in land use. According to the scientific explanation, the climate change is an adverse consequence resulted by concentration of Green House Gasses (GHGs) and tapping radiation in the atmosphere commonly denoted by global warming. It is well recognized that human activities are responsible for release of emission of GHGs such as $\mathrm{CO}, \mathrm{CO}_{2}, \mathrm{CH}_{4}, \mathrm{~N}_{2} \mathrm{O}, \mathrm{O}_{3}$, $\mathrm{CFC}_{5}$ etc. This process has resulted in increase in temperature, decrease in rainfall, frequent occurrence of extreme weather conditions such as intensive rains, flash floods, droughts, landslides, cyclones, lightening strikes, rise in sea water level, tornado type of winds, etc. It was recorded that doubling $\mathrm{CO}_{2}$ concentration will increase global average surface temperature between $1^{\circ} \mathrm{C}$ and $3.5^{\circ} \mathrm{C}$ year by 2100 , and further increase precipitation by $10 \%-15 \%$ (Crosson, 1997). In a nutshell, such global climate change has made adverse impacts on eco-systems and society in a broad variety.

Agricultural systems are highly affected by climate change and variations as cultivation of crops and livestock management practices are highly dependent on climatic factors. Developing countries are highly vulnerable to climate change (UNDP, 2007). Further, poor communities in rain-fed agricultural areas are more vulnerable to adverse climatic conditions. In fact, poverty and vulnerability show a significant correlation. In developing countries, the adaptive capacity is rather low due to technological, economic, and also non-economic factors. Same reasons are responsible for non-adaptation of mitigation measures.

Adaptation and mitigation are two major phenomena used to address global climate change issues and agriculture plays a vital role in achieving the goals expected to resilient the environment. The strong association between agriculture and climate change has been well identified and documented. In addition to existing efforts, different agricultural systems can be developed and executed to improve food security and living standards of the rural communities, provide climate change mitigation methods and adaptation processes. Therefore, new approaches for agricultural development are warranted in the present context, especially to deal with climate change and variations observed. As a result, this novel concept Climate Smart Agriculture emerged in 2010. The international agencies such as United Nations Food and Agriculture Organization (FAO) and World Bank are working for it to evolve a road map. The knowledge generation has emerged, and it is now necessary to find dissemination mechanism to reach the end users. The FAO discussed strategies needed for climate-smart agriculture. It is defined as agriculture that sustainably increases productivity, resilience (adaptation), reduces/removes GHGs (mitigation), and enhances achievement of national food security and development goals. The climate smart agriculture includes many of the field based sustainable agronomic and land management practices such as conservation tillage, residue management, agro-forestry, green technology, and others. It is also important to note that climate smart agriculture incorporates integrated planning of land agriculture, fisheries and water use at different scale such as local, watershed, regional, etc. An individual farmer might adopt climate smart practices by switching vulnerable activities to that are resistant to climate signals (Seo, 2006). As an example, farmer can change from crops to heat tolerant animals as goats. 
The new concept has emerged to deal with mitigation and adaptation necessary to resilient the vulnerable environments disturbed by climate change and variations. Now it is necessary to develop and deploy a viable knowledge dissemination approach to deliver knowledge elements pertaining climatic factors to ultimate clientele - to farmers.

Climate Field Schools (CFSs) are based on the experiences obtained with Farmer Field School sand follow same methodology. The agricultural extension systems have to be reoriented the framework to simulate participatory methods and fortify farmers collective decision making ability. Farmers should be convinced that use of climate forecast information would increase their benefit and the resilience of their system to the extreme climate events. It has to be mentioned that the outcomes of research evidence are very much confined to Indonesia and Philippines as they were the pioneering countries experimented this innovative agricultural extension approach. Hence, empirical evidence on its practical application is much limited. Sri Lanka has a diverse agroecological regions and as a result, the effect of climate change also varies. Therefore, appropriate mitigation, and adaptation measures have to be employed. In this connection, CFS is a viable dissemination technique.

\section{References}

1. Crosson, P. (1997), Impacts of Climate change on Agriculture, Climate Issues Brief No.4, Resources for the Future, Washington, DC.

2. IPCC (2007). Working Group II. Impacts, Adaptation and Vunerablity. Intergovernmental Panel on Climate Change. Fouth Assessment.

3. Seo, S.N. (2006). Modeling farmer responses to climate change: Climate change impacts and adaptations in livestock management in Africa. PhD Dissertation, Yale University. P.218.

4. UNDP. (2007). Fighting Climate Change: Human Solidarity in a Divided World. Human Development Report, 2007/08, Macmillan, New York, USA.

Mahinda Wijeratne.

Faculty of Agriculture,

University of Ruhuna,

Mapalana, Kamburupitiya, Sri Lanka.

Correspondence: mahindaw@agecon.ruh.ac.lk 